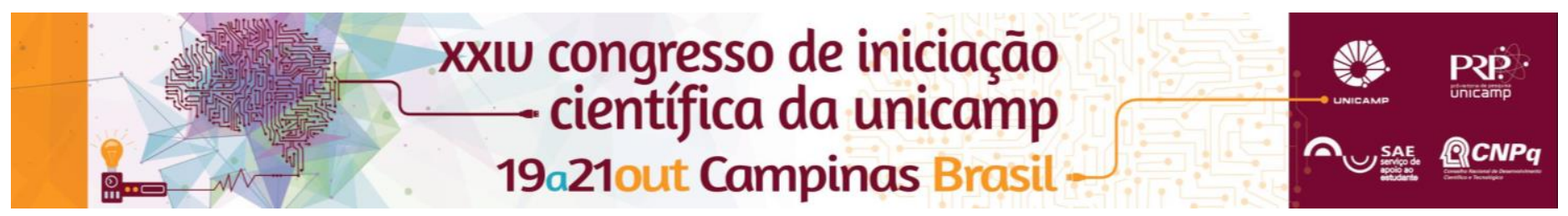

\title{
UTILIZAÇÃO DA ESTRUVITA FORMADA NA PRECIPITAÇÃO QUÍMICA DA AMÔNIA COMO FORMA DE NUTRIENTES PARA PLANTAS
}

\author{
João Pedro de Oliveira Ferreira (IC)*, Jorge Luiz da Paixão Filho (PG), Dailto Silva (PQ), Jerusa Schneider (PQ)
}

\begin{abstract}
Resumo
O projeto teve como objetivo avaliar o potencial da estruvita na liberação de nutrientes essenciais para o desenvolvimento de plantas. Para isso, foi instalado um experimento em casa de vegetação localizada na Faculdade de Engenharia Agrícola. A cultura utilizada foi a alface lisa, cultivar Regiane. Após colhidas, a parte aérea foi separada da radicular, pesadas e colocadas cada parte em sacos para serem levadas à estufa, a análise de massa fresca da parte aérea (MFPA) e número de folhas (NF) maiores ou iguais a $6 \mathrm{~cm}$. Concluiu-se que o tratamento que recebeu apenas estruvita com o dobro da dose recomendada de $\mathrm{P}$ apresentou, em média, o maior número de folhas e uma maior produção de fitomassa com tendência de aumento de produção conforme a dosagem de estruvita era aumentada. Além disso, o tratamento que recebeu estruvita+carnalita com o dobro da dose recomendada de $\mathrm{P}$ apresentou resultados próximos ao do adubo comercial NPK 10:10:10.
\end{abstract}

Palavras-chave: Lixiviado de aterro sanitário, Fertilizante sustentável, Fósforo, Carnalita

\section{Introdução}

$\mathrm{O}$ estudo da estruvita $\left(\mathrm{MgNH}_{4} \mathrm{PO}_{4} 6 \mathrm{H}_{2} \mathrm{O}\right)$ como fonte alternativa de nutrientes vai ao encontro das necessidades humanas, pois em sua fórmula molecular apresenta o fosfato além de magnésio e amônia que são essenciais na agricultura ${ }^{1}$. A possibilidade de uso da estruvita como fonte de nutrientes para plantas pode vir a tornar o lixiviado de aterro sanitário uma fonte alternativa para o fornecimento de fertilizantes a base de fósforo ${ }^{2}$. $O$ projeto teve como objetivo avaliar o potencial da estruvita formada a partir da precipitação química de lixiviado proveniente de aterro na liberação de nutrientes essenciais para o desenvolvimento de plantas.

O delineamento experimental utilizado foi inteiramente casualizado sendo constituído de oito tratamentos contendo doses de estruvita (E) e estruvita+carnalita (EC), determinadas com base na quantidade de fósforo total do precipitado obtido, análise do solo e nas recomendações de adubação para alface, além dos tratamentos controles (um tratamento sem fonte de nutriente e outro com adubação NPK - fórmula 10:10:10), com quatro repetições totalizando 32 vasos.

\section{Resultados e Discussão}

Foi escolhida a análise de MFPA e NF por serem os melhores parâmetros de produção vegetal e por que são avaliados pelos consumidores no momento da compra. Observou-se que o tratamento que recebeu apenas estruvita com o dobro da dose recomendada de $\mathrm{P}$ foi o que teve a maior produção de MFPA e NF, $65,88 \%$ e $21,31 \%$, respectivamente, a mais que o tratamento que recebeu o adubo comercial NPK 10:10:10 (Figura 1).

A formação de estruvita em ensaios de precipitação da amônia já foi observado em diversos trabalhos. No entanto, nesse trabalho foi observado a formação de outro mineral em conjunto com a estruvita. $O$ mineral encontrado é a carnalita $\left(\mathrm{KMgCl}_{3} \cdot 6\left(\mathrm{H}_{2} \mathrm{O}\right)\right.$. A aplicação de estruvita + carnalita com o dobro de fósforo apresentou desenvolvimento semelhante ao observado com a adubação NPK.

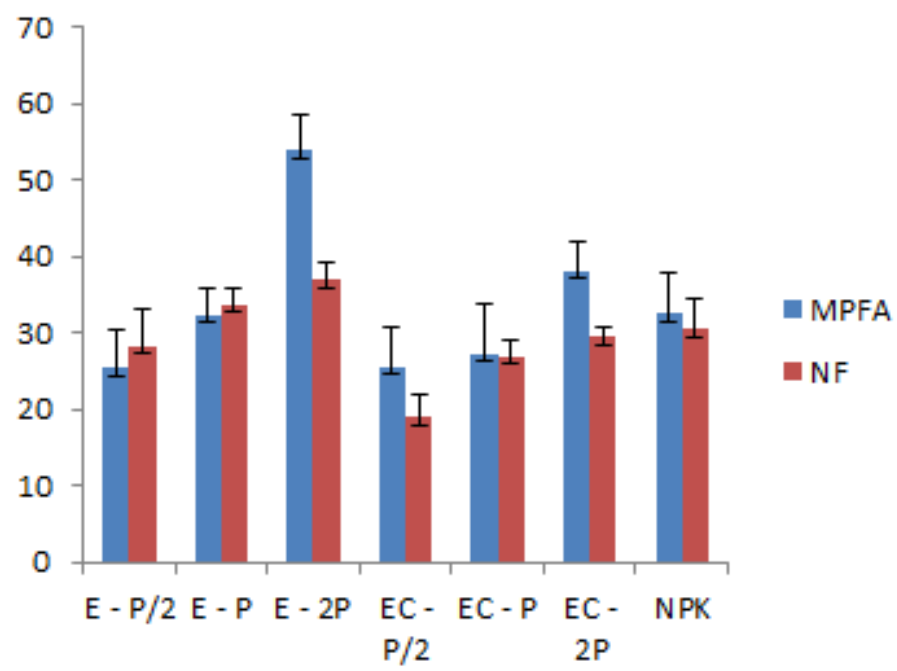

Figura 1. Valores de MFPA e NF em gramas para os tratamentos com estruvita, estruvita+carnalita, com a metade da dose recomendada de $P(P / 2)$, recomendada (P) e o dobro 2P e NPK com a dose recomendada de $\mathrm{P}$. Barras verticais representam o desvio padrão; $n=4$.

\section{Conclusões}

- O uso da estruvita e da carnalita como fonte de nutrientes pode ser uma alternativa para substituir os fertilizantes convencionais.

- O aumento da dose aplicação de estruvita e carnalita aumentou o número de folhas e MFPA do vegetal analisado.

- Novas pesquisas com diferentes dosagens devem ser realizadas.

\section{Agradecimentos}

Instituição de fomento: Conselho Nacional de Desenvolvimento Científico e Tecnológico - CNPq

${ }^{1}$ DIAS, V. P.; FERNANDES, E. FERTILIZANTES: UMA VISÃO GLOBAL SINTÉTICA . BNDES Setorial, Rio de Janeiro, n. 24, p. 97-138, set. 2006

${ }^{2}$ MASSEY, M. S.; DAVIS, J. G.; IPPOLITO, J. A.; SHEFFIELD, R. R Effectiveness of recovered magnesium phosphates as fertilizers in neutral and slight alkaline soils. Agronomy Journal, vol. 101, Issue 2, 2009. 